\title{
PUBLIC PARTICIPATION IN IMPLEMENTATION OF NATIONAL SECURITY POLICY: CASE STUDY OF BORDER SECURITY POLICE IN SANGKHLA BURI DISTRICT, KANCHANABURI PROVINCE, THAILAND
}

\author{
Boriboon Chalong
}

Suan Sunandha Rajabhat University, Bangkok, Thailand

The objective of this research is to examine the level of direct participation of the Sangkhla Buri District residents in the implementation of national security policy. The results of this research helped us formulate recommendations on how to solve the problems related to participation of residents in this process. Population of this study includes the residents of 3 sub-districts of Sangkhla Buri District. The sample size is 400 and the data has been collected using questionnaires. Indepth interviews have been also conducted to explore the opinions of the local leaders and the related government officials. The data has been analyzed to track the statistical impacts. The research study expects to find the relationship between independent variables, which are democratic knowledge and attitude towards democracy, and the dependent variable, i.e., participation of residents in the implementation of national security policy.

Keywords: public participation, national security, border security, policy, residents, Thailand.

\section{Introduction}

Public participation is a political principle or practice, also be recognized as a right. The term "public participation", often referred to as P2 by the practitioners in the field, is sometimes used interchangeably with "stakeholder engagement" and/or "popular participation". Most experts/advisers are of the opinion that these issues are of great public importance since population at last demonstrates strong interest in the outcomes of policy choices, in design and implementation of various public policies and in the institutions that are supposed to deliver them. Yet overall, the level of public participation and citizens' engagement in these decision-making processes tends to be low. The general public is often very little informed about what is being discussed and decided by authorities, even though all

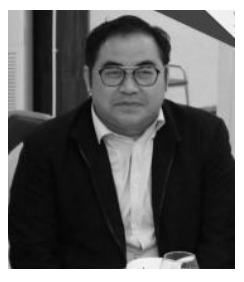

\section{Boriboon Chalong}

Master of Public Adminstration

Lecturer in Suan Sunandha Rajabhat University, Bangkok, Thailand

Researcher in Faculty of Political Science, Thammasat University, Bangkok, Thailand

Expert of National Economic and Social Advisory Council Thailand

Science interests: national policy, legislative system, Governance, economy regulation

E-mail: Boriboon.chalong@hotmail.com 
these decisions are supposed to be 'in the public interest'. This has even been the case about what, in developing countries, is the most fundamental manifestation of the sociopolitical contract between state authorities and citizens - the constitution. Similarly to this, quite many security sector advisers are convinced that security sector reforms should be the matter of specialists only, even though public security is also of direct and immediate interest for all citizens in a country/region.

In Thailand, the public participation principle has been mentioned in The Constitution of the Kingdom of Thailand as of 1997.

To contribute to the existing literature on the issue, this study adopts the theoretical model from the study by Mulligaman (2002) to analyze the relationship between democratic knowledge and attitude towards democracy among the residents of Sangkhla Buri District, Kanchanaburi Province, Thailand.

\section{Objectives}

1. The research is to examine the relationship between demographic factors and the level of public participation among Sangkhla Buri District residents in part regarding the implementation of national security policy.

2. The research is also to analyze the relationship between democratic knowledge and the attitude towards democracy with the level of public participation of Sangkhla Buri District residents in the implementation of national security policy.

\section{Literature review}

\section{The Concept of Public Participation}

Participation is the process through which stakeholders influence and share control over the priorities' setting, policy-making, resources' allocation and access to public goods and services (World Bank Group, 2005). Participation in planning is widely considered to improve the quality and effectiveness of decision-making as it widens the knowledge base, stimulates creativity and provides social support for policies (Pretty et al., 1995; Pelletier et al., 1999; Monnikhof and Edelenbos, 2001; Burby, 2003; Leeuwis, 2004). Participation in this context means involvement in the decision-making process of individuals and groups that are either positively, or negatively affected by planned intervention (e.g., a project, a program, a plan, a policy) or are interested in it (Andre' et al., 2006). This indirectly acknowledges the fact that the public has the right to be timely informed and to be proactively involved in a meaningful way in the proposals which may affect their livelihood.

\section{The Importance of Public Participation}

It is widely believed that public participation contributes to better projects, better development and collaborative governance. However, traditional forms of (ex-post) public involvement like information and court appeal, typical for the so-called "decide-announcedefend" style policy-making, have often proven to be inadequate, as they institutionalize hindrance power in legislative procedures and do not allow for (ex ante) constructive contributions to planning. In the majority of Western countries more constructive and cooperative forms of planning, like consultations and active, early involvement are now supported and actively promoted, for instance by the EU among its member states (WFD, 


\section{PUBLIC PARTICIPATION IN IMPLEMENTATION OF}

Art.14). The research has shown that these forms of participation can be advantageous for the speed and quality of planning decisions implementation, but not without certain pitfalls (Davies, 2001; Klijn and Koppenjan, 2003; Enserink and Monnikhof, 2003; Pahl-Wostl, 2002). This is especially relevant for strategic planning, in part of discussing plans, policies and programmes at the national level. Institutionalized and well-organized stakeholder groups are considered as partners in the planning process and procedures directly related to the national security policy planning.

\section{The Process of Public Participation}

Public Participation Best Practices Principles are listed in many documents and websites. Using many of those, we have come up with the following list of core values in the practice of public participation:

The public should have a say in decisions about the actions that affect their lives. It has the right to be informed early and to be proactively involved in a meaningful way;

Participants should get all information they need to participate in a meaningful way to increase the interest and motivation to participate; this includes the promise that the public's contribution will influence the final decision taken by the authorities;

The public participation process should respect historical, cultural, environmental, political and social backgrounds of the communities which are affected by a proposal, including less represented groups like indigenous peoples, women, children, the elderly, and the poor;

The public participation process involves participants in defining how they participate and promotes equity between actual and future generations in a perspective of sustainability.

In respect to the governance principles previously identified, public participation should be:

Initiated very early into the life-cycle of a planned intervention, and sustained during its entire life.

Well planned and structured. All actors should know the aims, rules, organizational procedure and expected outcomes from the undertaken PP process.

Tiered and optimized. Any PP program should take place at the most efficient level of decision-making, e.g., at the policy, plan, program or project levels.

Led by the neutral authority in its formal or traditional sense and following the rules known and accepted by all parties. PP needs to follow some rules of ethics, professional behavior or moral obligations.

Focused on negotiable issues relevant to decision-making. Because consensus is not always feasible, PP needs to hear about values and interests of participants, and to focus on negotiable issues.

As we can read from the above, and what was also mentioned by Palerm (2000), public participation has been increasingly recognized as one of the most important assets for the environmental impact assessment. Different forms and levels of participation might be relevant for different phases in implementation of national security policy processes. In order to be effective public participation should be well organized and well managed.

This study on the level of people's participation was based on the Ladder of Citizen Participation by Sherry R. Arnstein (see the figure below). 


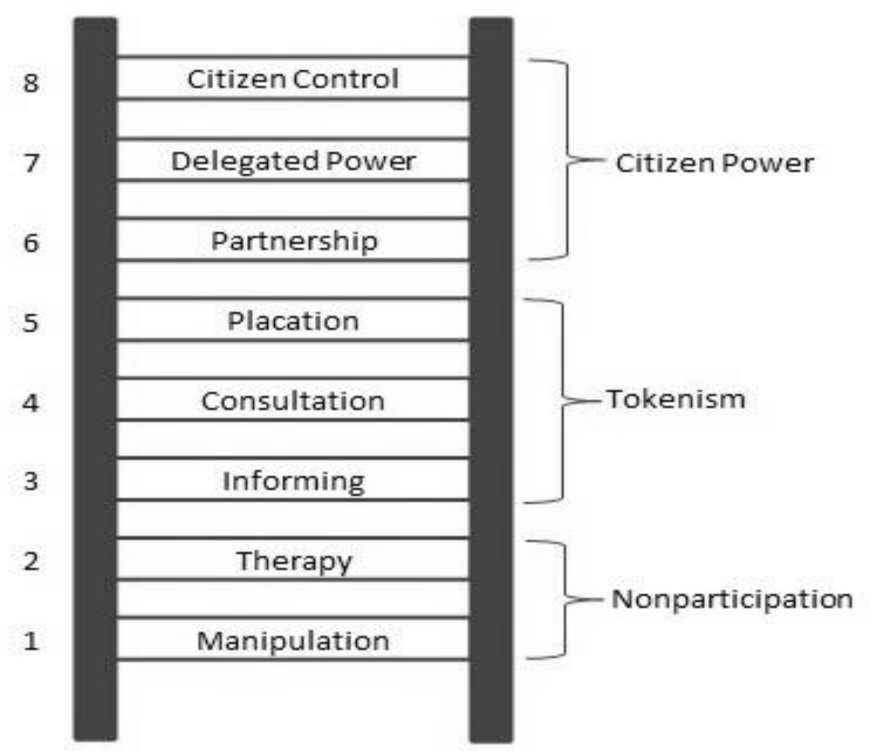

Figure 1. The Ladder of Citizen Participation

(Source: Arnstein, 1969)

Sherry R Arnstein (1969) suggested this typology with its eight levels of participation that may help with the analysis of this rather confusing issue. For illustrative purposes, these eight types are arranged in a ladder pattern, each rung corresponding to the extent of citizens' power in determining the end product. The bottom rungs of the ladder are (1) Manipulation and (2) Therapy. These two rungs describe the levels of "non-participation" that serves to substitute for genuine participation. Their real objective is not to enable people to participate in planning or conducting programs, but to enable power holders to "educate" or "cure" the participants. Rungs 3 and 4 progress to the levels of "tokenism" that allow the have-nots to hear and to have a voice: (3) Informing and (4) Consideration. When they are offered by power holders as the total extent of participation, citizens may indeed hear and be heard. But under these conditions they lack the power to insure that their views will be heeded by the powerful. When participation is restricted to these levels, there is no follow-through, no "muscle," hence, no assurance of changing the status quo. Rung (5) - Placation, is simply a higher level tokenism because the ground rules allow have-nots to advise, still retaining for the power holders the continued right to decide. Further up the ladder are the levels of citizen power with the increasing degrees of decision-making. Citizens can now enter into a (6) Partnership that enables them to negotiate and engage in trade-offs with traditional power holders. The topmost rungs - (7) Delegated Power and (8) Citizen Control - mean that the citizens may obtain the majority of decision-making seats, or full managerial power.

Obviously, the eight-rung ladder is a simplification, but it helps to illustrate the point that so many have missed - about the significant gradations in citizen participation. Knowing these gradations makes it possible to cut through the hyperbole to understand the increasingly strident demands for participation from the have-nots as well as the gamut of confusing responses from the power holders.

Sunee Mulligaman (2002) divides the level of public participation into 6 levels: (1) Sharing, (2) Join the discussion, (3) Joint decision-making, (4) Co-Cooperate, (5) Follow up, monitoring and evaluation, and (6) Get Results. This author has actually studied people's 


\section{PUBLIC PARTICIPATION IN IMPLEMENTATION OF}

participation in management of the community garbage problems, resulting from consumption, with its obvious direct effects on people's health, their well being, their quality of life and the environment overall.

At some point, the garbage volume increases to the level at which the local administrator is already unable to handle the aggravated problems. One of the several ways to tackle these problems is the reduction of garbage volume through garbage separation. One portion of garbage could be reused or recycled while the other portion could produce organic fertilizer thus reducing the volume of garbage to be disposed. However, such garbage separation method must be be acceptable for the people since they are supposed comply by separating garbage before disposing it.

This research has found two approaches to this. The involvement of an education mechanism means teachers and students start participating in garbage separation activities under the garbage management program. Students bring various reusable items such as paper, glass bottles from home to school so that to sell these items to scavengers in their shops. Teachers explain students how to convert various reusable items into other useful items such as paper lampshade from discarded paper or plastic flowers from discarded plastic items. Students who brought garbage that would later be sold would earn merit points accumulated on their accounts in the merit bank. Later on, these merit points could be exchanged for consumable items.

Another feature of this education mechanism is the United Recycle Powers Program, which requires students to separate the garbage at home and provide it to the school for sale, the proceeds to be used to cover various school activities. Garbage separation shall later be introduced to the community in which the school is situated by the students, the teachers, and other community members.

Community Mechanism Garbage separation campaign aimed to educate the community shall be launched continually. it is supported by the local administration which is responsible for the provision of the separated garbage collection equipment so that to collect garbage which is already separated. It is concluded from the research that garbage separation prior to disposal reduces garbage volume, thus helping to solve garbage problems. Direct participation of the local people, primarily students and teachers, is the most effective element in this process.

\section{Methodology}

A questionnaire was constructed and administered to Sangkhla Buri District residents in the areas of Sangkhla Buri district, Kanchanaburi Province, Thailand. The Likert fivepoint scale questionnaire was designed to investigate the factors influencing the level of public participation from the perspective of Sangkhla Buri District residents.

The population included all residing in Sangkhla Buri, Thailand. The simple random sampling technique was performed to obtain the sample group that included 400 residents. Taro Yamane (1973) technique was utilized to obtain an accurate sample group. The dependent variables of this study included the demographic variables, democratic knowledge, and attitude towards democracy. The independent variable is the level of public participation (Mulligaman, 2002). Descriptive statistics applied in this research, including percentage, mean, and standard deviation. In addition, 30 pilot questionnaires were tested and each 
question had to pass the Cronbach Alpha criteria with at least 0.7. Moreover, the validity of the questions was evaluated using the IOC technique with three experts.

\section{Results}

The total of 400 residents was chosen from 3 sub-districts of Sangkhla Buri district, Thailand. The findings of this study revealed the following.

Table 1. Demographic Characteristics of the Respondents (compiled by the author)

\begin{tabular}{|c|c|c|}
\hline Demographics & Sample $(\mathrm{N}=400)$ & Percentage \\
\hline \multirow[t]{2}{*}{ Gender } & Male & 55.0 \\
\hline & Female & 45.0 \\
\hline \multirow[t]{6}{*}{ Age } & Less than 20 & 17.8 \\
\hline & $20-29$ & 12.3 \\
\hline & $30-39$ & 14.0 \\
\hline & $40-49$ & 19.0 \\
\hline & $50-59$ & 19.3 \\
\hline & $60+$ & 17.8 \\
\hline \multirow[t]{5}{*}{ Level of Education } & Elementary education & 38.0 \\
\hline & High school education & 43.0 \\
\hline & Bachelor's degree & 14.8 \\
\hline & Master's degree & 1.5 \\
\hline & Other & 2.8 \\
\hline Level of Income & Less than 5,000 & 46.5 \\
\hline \multirow[t]{6}{*}{$(32$ Baht $=$ US\$1) } & $5,001-10,000$ & 37.5 \\
\hline & $10,001-20,000$ & 10.8 \\
\hline & $20,001-30,000$ & 2.8 \\
\hline & $30,001-40,000$ & 1.3 \\
\hline & $40,001-50,000$ & 0.5 \\
\hline & More than 50,000 & 0.8 \\
\hline \multirow[t]{4}{*}{ Religion } & Buddhism & 94.50 \\
\hline & Islam & 4.29 \\
\hline & Christianity & 1.20 \\
\hline & Other & 0.01 \\
\hline
\end{tabular}

Table 1 presents the participants' demographics. The majority of the participants were 40-60 years old, comprising approximately half of the totality. There was a roughly even distribution of men and women with $55 \%$ for men and $45 \%$ for women. Most of the respondents were married $(66.8 \%)$, while $33.3 \%$ were still single. The average income of the surveyed households was reported to be from less than 5,000 Baht per month $(46.5 \%)$ to 


\section{PUBLIC PARTICIPATION IN IMPLEMENTATION OF}

5,001-10,000 Baht per month (37.5\%). Regarding the religion, 94.5\% of the respondents are Buddhists, while $4.29 \%$ are Muslim and $1.2 \%$ are Christians.

Table 2. Public Participation Results (compiled by the author)

\begin{tabular}{|l|l|l|c|}
\hline \multicolumn{1}{|c|}{ Level of Participation } & Mean & S.D. & Rank \\
\hline \multicolumn{1}{|c|}{ Variables } & & & \\
\hline Sharing & 4.73 & 0.998 & 1 \\
\hline Join the discussion & 4.71 & 0.876 & 2 \\
\hline Joint decision-making & 4.66 & 0.783 & 3 \\
\hline Co-Cooperate & 4.45 & 0.758 & 4 \\
\hline $\begin{array}{l}\text { Follow up, monitoring and } \\
\text { evaluation }\end{array}$ & 4.43 & 0.770 & 5 \\
\hline Get Results & 4.41 & 0.786 & 6 \\
\hline
\end{tabular}

The hypothesis testing about the relationships between democratic knowledge and attitude towards democracy are shown in the tables below.

The relationship between democratic knowledge and public participation is shown in Table 3.

Table 3. Relationship between Democratic Knowledge and Public Participation (constructed by the author)

\begin{tabular}{|c|c|c|c|c|}
\hline & \multicolumn{3}{|c|}{ Level of Participation } & \\
\hline Democratic Knowledge & High & Medium & Low & $\begin{array}{c}\text { Total } \\
\text { (persons) }\end{array}$ \\
\hline High & 78 & 53 & 28 & 159 \\
\hline Medium & 65 & 38 & 19 & 122 \\
\hline Low & 35 & 66 & 18 & 119 \\
\hline Total (persons) & 178 & 157 & 65 & 400 \\
\hline
\end{tabular}

From the above table we can see that democratic knowledge has a significant relationship with the level of public participation. 
Table 4. Relationship between Attitude towards Democracy and Public Participation (constructed by the author)

\begin{tabular}{|c|c|c|c|c|}
\hline Attitude towards & \multicolumn{3}{|c|}{ Level of Participation } & \\
\hline Democracy & High & Medium & Low & $\begin{array}{c}\text { Total } \\
\text { (persons) }\end{array}$ \\
\hline High & 78 & 53 & 28 & 159 \\
\hline Medium & 65 & 38 & 19 & 122 \\
\hline Low & 35 & 66 & 18 & 119 \\
\hline Total (persons) & 178 & 157 & 65 & 400 \\
\hline
\end{tabular}

The findings presented in the tables above reveal that both variables in question democratic knowledge and attitude towards democracy - are important in explaining the level of public participation. In the case of Sangkhla Buri district, Kanchanaburi Province, in particular these two variables play a significant role and directly influence the level of public participation among the local residents.

\section{Conclusions and Discussion}

This study has assessed the relationships between democratic knowledge and attitude towards democracy with level of public participation. The findings of this study have both theoretical and applied implications for further studies on the issues of public participation. Understanding the variables that are influencing residents' participation level can help local authorities and policymakers better assess residents' involvement in national security policy implementation. Furthermore, it is quite encouraging to see that the residents are aware of the national security policy as such.

This study is not without its limitations. As mentioned previously, the small sample size of our population could have led to presentations of rather subjective opinions and bias. More qualitative research can produce more tentative findings, but it cannot represent the whole population. Future studies could pursue the same line of enquiry through quantitative surveys. Secondly, as the level of public participation is likely to change in the course of time, it is important to revisit the area in the future to determine changes in residents' participation.

\section{Acknowledgement}

The author would like to thank the Research and Development Institute, Suan Sunandha Rajabhat University, Bangkok, Thailand for financial support.

\section{References:}

Andre', P., Delisle, C. \& Reve'ret, J. (2004), Environmental Assessment for Sustainable Development: Processes, Actors and Practice. Presses Internationales Polytechnique, Montreal. 


\section{PUBLIC PARTICIPATION IN IMPLEMENTATION OF}

Arnstein, S. R. (1969). A Ladder of Citizen Participation. JAIP, 35,4: 216-224.

Burby, R.J. (2003). Making plans that matter, citizens' involvement and government action. Journal of the American Planning Association, 69: 33-47.

Campbell, D.J. (2008). The basic concept for the democracy ranking of the quality of democracy. Vienna: Democracy Ranking.

Davies, A. (2001). What silence knows - planning, public participation and environmental values. Environmental Values, 10: 77-102.

Enserink, B. \& Monnikhof, R. (2003). Impact assessment and public participation: facilitating co-design by information management - an example from The Netherlands. Journal of Environmental Planning and Management, 46, 3: 315-44.

Klijn, E.H. \& Koppenjan, J. (2003). Rediscovering the citizen: new roles for politicians in interactive policy making. In: McLaverty, P. (Ed.), Public Participation and Innovations in Community Governance, Ashgate, Aldershot: 141-64.

Leeuwis, C. (2004), Communication for Rural Innovation, Rethinking Agricultural Extension, $3^{\text {rd }}$ ed., with contributions from Anne van der Ban, Blackwell Publishing, Ames, IA.

Mollicaman, S. (2002). Constitution and Public Participation in the Conservation of Natural Resources and the Environment. Bangkok: Chulalongkorn University Press.

Monnikhof, R. \& Edelenbos, J. (2001). Into the fog. Stakeholder input in participatory impact assessment, impact assessment and project appraisal. Journal of the International Association for Impact Assessment, 19, 1: 29-39.

Pahl-Wostl, C. (2002). Participative and stakeholder-based policy design, analysis and evaluation processes. Integrated Assessment, 3: 3-14.

Pelletier, D., Kraak, V., McCullum, C., Uusitalo, U. \& Rich, R. (1999). The shaping of collective values through deliberate democracy: an empirical study from New York's North Country. Policy Science. 32: 103-31.

Pretty, J.N., Guijt, I., Thompson, J. \& Scoones, I. (1995). Participatory Learning and Action. A Trainer's Guide. International Institute for Environment and Development (IIED), London.

Sharon, S. \& Saul, M. (1996). Social psychology. Boston: Houghton Mifflin.

Stipack A.Y. (1979). Government spending and economic growth. Journal of Applied Economics, 26 (1): 46.

World Bank Group, (2005). Poverty reduction, strategy formulation organizing participatory processes in the PRSP. What is participation and what role can it play in the PRSP? available at: www.worldbank.org/participation/PRSP/what.htm (accessed January 2018).

Yamane, T. (1973). Statistics: An Introductory Analysis. New York: Harper and Row.

Paper submitted

Paper accepted for publishing

Paper published online
04 June 2018

18 August 2018

30 September 2018 